\title{
SPE 112184
}

\section{Case Study: Analysis of the Characteristics of the Damage to Dujiatai Low- Permeability Reservoir by Water Injection and Research of Damage Removal Methods}

\author{
Zhao Zhengchao, SPE, Institute of Mechanics, Chinese Academy of Sciences, Liu Wei, SPE, Liaohe Oilfield \\ Company of PetroChina
}

Copyright 2008, Society of Petroleum Engineers

This paper was prepared for presentation at the 2008 SPE International Symposium and Exhibition on Formation Damage Control held in Lafayette, Louisiana, U.S.A., 13-15 February 2008.

This paper was selected for presentation by an SPE program committee following review of information contained in an abstract submitted by the author(s). Contents of the paper have not been reviewed by the Society of Petroleum Engineers and are subject to correction by the author(s). The material does not necessarily reflect any position of the Society of Petroleum Engineers, its officers, or members. Electronic reproduction, distribution, or storage of any part of this paper without the written consent of the Society of Petroleum Engineers is prohibited. Permission to reproduce in print is restricted to an abstract of not more than 300 words; illustrations may not be copied. The abstract must contain conspicuous acknowledgment of SPE copyright.

\section{Abstract}

Dujiatai reservoir has an oil bearing area of $37.2 \mathrm{~km}^{2}$ with the OIP of $2409 \times 10^{4} \mathrm{t}$, burial depth of $-2650 \sim-2960 \mathrm{~m}$, porosity of $15.1 \%$ and permeability of $37.7 \times 10^{-3} \mu \mathrm{m}^{-2}$. In general, the reservoir is produced initially under natural energy by elastic drive and solution gas drive and development with water injection is tested in the later stage due to fast pressure decline and subsequent substantial production decline. During the water injection field test, although the water to be injected had been filtered to a fine degree, the water injection pressure increased substantially after a short time and water injection became difficult and some of the injectors were forced to be shut in because no water could be injected. The paper introduces the analysis results of the tests on water injection damage to Dujiatai low permeability reservoir. (1) Solid particles entered the reservoir, forming blockage due to the small throats of filtration with the average radius of the throats of about $1.0 \mu \mathrm{m}$; (2) Because the injected water was not treated against swelling, clay swelled, forming blockage due to the medium to strong water sensitivity of the reservoir; (3) Because of the medium to strong velocity sensitivity of the reservoir, fine particles staying in a unconsolidated manner on the borehole walls or inner surface of the base rocks fell out, migrated and piled up at the throats, forming blockage; (4) The scaling tendency of $\mathrm{CaCO}_{3}$ of the injected water was obvious and the scales adhered to the inner surface of the throats, reducing the filtration radius of the throats; (5) The water injection pipeline was corroded seriously and the suspended particle content at the outlet of the filtering station reached the standard, but it exceeded the standard after going through the water injection pipeline and reaching the wellhead and it was even worse when it reached the bottom of the well.

The solutions for the water injection damage to Dujiatai low permeability reservoir are as follows. (1) Acidization or acid fracturing deeper into the formations with weak acids is conducted to erode the unstable migrating particles; (2)
Antiswelling agent is added to the injecting water to reduce clay swelling; (3) A secondary filtering unit is set up at the wellhead or the water injection pipeline is replaced with a corrosion prevention pipeline lined with fiberglass.

\section{Introduction}

Dujiatai reservoir has an oil bearing area of $37.2 \mathrm{~km}^{2}$ with the OIP of $2409 \times 10^{4} \mathrm{t}$, burial depth of $-2650 \sim-2960 \mathrm{~m}$, porosity of $15.1 \%$ and permeability of $37.7 \times 10^{-3} \mu \mathrm{m}^{-2}$. The oil bearing interval is large vertically with sandstone and mudstone alternating deposits, including three oil layer groups, six sandstone formations and 29 sublayers. The formations are highly heterogeneous from one another. The lithology is mainly light grey fine sandstone and siltstone, followed by pebbled sandstone and glutinite. The cementing material is made up of mainly argillaceous cement and calcareous cement with the argillaceous cement being unconsolidated with shale content of $10.3 \%$. The calcareous cement is consolidated and hard with the average calcic content of $11.3 \%$ and the cementing depends mainly on pore cementing. Horizontally, the distribution and development of the deposits are influenced greatly by the ancient landform with fan delta deposits as the major sedimentary facies, including underwater tributary channels, river mouth sand bars and frontal lice subfacies. The sand bodies are poorly connected laterally due to the control of narrow facies belts of the deposits. The permeability between the sand bodies and microfacies differs by several times to tens times. No large areas of continuous deposits are developed in general. The reservoir is highly heterogeneous horizontally with the major facies belts having good physical properties, welldeveloped pores and good connectivity. The minor facies belts have poor physical properties with poorly developed pores and poor connectivity ${ }^{[1]}$. The crude oil at the surface has the density of $0.8491 \mathrm{~g} / \mathrm{cm}^{3}$, viscosity $4.59 \mathrm{mPa} \cdot \mathrm{s} \sim$ $18.7 \mathrm{mPa} \cdot \mathrm{s}$, paraffin content $7.33 \% \sim 10.42 \%$ and freezing point $25.6^{\circ} \mathrm{C}$. The formation water is typical of sodium 
carbonate type of water with the total salinity of $3000 \sim 7000 \mathrm{mg} / \mathrm{L}$.

Dujiatai reservoir was initially developed mainly by elastic drive and solution gas drive and water injection development was tested later on due to quick pressure drop and substantial production decline. However, the water injection results were not satisfactory due to various reasons. Take Block XH27 as an example, which is a typical low permeability block with the original formation pressure of 29.23MPa. Because of the poor physical properties of the reservoir, large filtrational resistance and quick energy consumption, the formation pressure declines very quickly with the average decline rate of $23 \% \sim 25 \%$ per month. At present, the formation pressure stands only at $10.36 \mathrm{MPa}$. With the quick decline of formation pressure, production declines substantially. Many wells have to produce intermittently due to insufficient deliverability. The recovery percent of reserves is only $9.39 \%$ and the oil recovery rate is only $0.12 \%$.

Water injection development was tested in the later stage but problems soon occurred, such as high water injection pressure, difficult water injection and poor water injection results. Three water injection tests have been carried out in the block since it was put into development in 1978.

In Oct. 1984, water injection development was tested for the first time and 4 wells were converted into injectors. Among the 4 wells, two wells (Well H2-10-19 and H2-8-17) were confronted with high pressure during water injection with the pump pressure at $21.0-23.0 \mathrm{MPa}$ and injection rate at $283 \mathrm{~m}^{3} / \mathrm{d}$. The other two wells (well H2-9-18 and H2-8-19) experienced water injection at normal pressure with the water injection rate of $47 \mathrm{~m}^{3} / \mathrm{d}$ and they were shut in because no water could be injected into the formation 26days and one day later respectively. In Dec. 1986, high pressure water injection started in the two wells with the pump pressure at 19.8MPa and water injection rate at $299 \mathrm{~m}^{3} / \mathrm{d}$. In Sept. 1992, all the injectors were shut in because no water could be injected into the formation. By this time, cumulative water injection in the block reached $162256 \mathrm{~m}^{3}$. At stable water injection pressure, daily injection per well and apparent water injectivity index declined year by year with the daily injection per well declined from $149.5 \mathrm{~m}^{3} / \mathrm{d}$ in 1986 to $7 \mathrm{~m}^{3} / \mathrm{d}$ in 1990 and apparent water injectivity index from $7.9 \mathrm{~m}^{3} /(\mathrm{d} \cdot \mathrm{MPa})$ to $0.38 \mathrm{~m}^{3} /(\mathrm{d} \cdot \mathrm{MPa})$. Furthermore, the cumulative injection varied greatly from well to well with Well H2-8-19 injecting cumulatively $96894.0 \mathrm{~m}^{3}$, taking up $60 \%$ of the total volume while Well H2-10-19 injecting cumulatively only $4002.0 \mathrm{~m}^{3}$.

In March 2004, water injection development was tested for the second time and 5 wells were converted into injectors initially, all under high pressure water injection with the pump pressure at 16.7-19.2MPa and water injection pressure at $6.2-18.5 \mathrm{MPa}$ and injection rate at $30-90 \mathrm{~m}^{3} / \mathrm{d}$. In July 2004, injection stopped in all of the wells. Before injection stopped, water injection pressure increased by about 11.0MPa in Well H2-8-5219and H2-9-5218 and the cumulative water injection per well reached 2691.0$4624.0 \mathrm{~m}^{3}$.
The injected water in the two tests did not go through fine filtering and the water quality was not up to the standards. It was analyzed that the suspended particles caused serious formation damage, leading to water injection pressure increase and decrease of water injection and the final pause of water injection.

In 2005, the fine filtering system for injecting water was modified and the quality of water was up to the standards. Water injection was resumed in 6 wells in the block. Based on the performance of the block, the water injection rate in the injectors was adjusted. It can be seen from the water injection results that the water injection pressure of the 6 injectors has increased somewhat compared with the initial stage when water injection started in March 2004 and reinjection started initially in July 2005. Especially in the three injectors in the north of the reservoir (Well H2-8-5219, H29-5217 and H2-9-5218), injection pressure has increased substantially (over 10MPa). Since water injection was resumed, water injection has lasted for 13 months with the cumulative water injection of about $1.0 \times 10^{4} \mathrm{~m}^{3}$ per well. From the injection-production curves of two wells around the injectors that have been producing continuously, Well $\mathrm{XH} 27$ and H2-10-518, it can be seen no obvious water injection results can be observed in the oil wells. From the comprehensive production curves of the block, oil production has dropped from $21 \mathrm{t} / \mathrm{d}$ before water injection to present $15 \mathrm{t} / \mathrm{d}$ and the producing fluid level remains at about $1600 \mathrm{~m}$, so no obvious water injection results have been observed either.

Generalization of the three water injection tests indicates that it is difficult to carry out water injection development in Block Huan27 and the factors affecting water injection results are complicated.

\section{Analysis of microscopic pore throat structural features}

Analysis of the core samples indicates (Table 1 and 2) that the pore structure in Dujiatai reservoir falls into the low permeability, medium porosity, fine throats and uneven distribution category. The pores are mainly original residual intergranular pores, followed by corroded pores. The average diameter of the medium pores is $83.89 \mu \mathrm{m}$. Due to secondary activities, the original pore throats are reducing or even blocked and the throats are fine throats with the average median grain size of $2.78 \mathrm{~mm}$. The pore throat ratio is high, usually at 10-100 with the average at 107.23. The coordinate number is low, usually at 1.5-2.8 with the average at only 2.3. The pore throats are undeveloped and uneven with the average coefficient of uniformity being 0.249 , so falling into the nonuniform category. The rock particles are closely arrayed mainly in mosaic style with porous cementing as the major pore cement packed in the pore throats, blocking the throats. In addition, the average radius of the effective pore throats is only $8.02 \mu \mathrm{m}$ and the average max. radius of connected pore throats is only $13.41 \mu \mathrm{m}$, so the throats for providing filtration capability are too small. The major effective pore volume takes up $14.65 \%$ with $8.48 \%$ of pore 
volume greater than $10 \mu \mathrm{m}, 4.7 \%$ pore volume greater than $16 \mu \mathrm{m}$, which indicates there are too few large throats. On the contrary, non effective pore volume takes up $74.4 \%$ and pore volumes smaller than $0.1 \mu \mathrm{m}$ takes up $36.5 \%$, which indicates there are two many pore throats contributing little or nothing to permeability. At the same time, due to strong compaction, the particles are closely tied together; the throats are narrow and bent. Coupled with secondary growth of quartz, the inner walls of pores become unsmooth and carbonate is jammed between grain particles, resulting in accumulation of clay minerals such as kaolinite, increasing the tortuosity of throats. The structure coefficient which reflects tortuosity is as high as 3.13 and the ejection efficiency which reflects recovery factor is only $31 \%$ - 59\% with the average of $44 \%$. Based on the analysis of the core samples in terms of pore structure, distribution pattern of throat peak values, cumulative distribution pattern of different throat radius and its contribution to permeability, it can be concluded that the microscopic heterogeneity of the block is strong and the filtrational throats are narrow. Narrow throats and its large percentage contribute the most to permeability, so water injection development is subject to the following damage. The fine solid particles carried in the injected fluids enter the reservoir together with the injected fluids, blocking pore throats, thus leading to decrease of reservoir permeability. During water injection, once slight clay swelling due to hydration occurs and particles migrate in the formation, the filtration capability of the small throats will be damaged greatly. If scale is formed in the formation after injected water enters, the filtration capability of the small throats will also be greatly affected. If the reservoir has large percentage of velocity sensitive minerals and water injection rate is too high during injection, the velocity sensitive minerals will migrate, causing the narrow throats to be blocked and the reservoir permeability will be damaged. Microscopic pore throat features of the reservoir are the basic cause for damage during water injection.

\section{Analysis of mineral composition features of the reservoir}

X-ray diffraction analysis of core debris (Table 3 and 4) indicates that the core debris is made up of mostly quartz and feldspar and small amount of calcite and clay minerals and minute quantity of dolomite, analcite and siderite in some intervals. The shallow intervals have the most clay minerals, made up of illite/smectite mixed layers, chlorite and illite, some kaolinite and smectite in some intervals. Because the core has illlite/smectite mixed layers and smectite, which are highly water sensitive, smectite will swell obviously during water injection. Kaolinite and illite do not swell easily, but they are highly sensitive to velocity. The core has chlorite, which can release ferric ions in contact with hydrochloric acid and when acid fluid is consumed, $\mathrm{PH}$ value will rise and the ferric ions will deposit, producing acid sensitivity. It is generally believed that the reservoir conditions are poor if the clay mineral content is over $5 \%$. If the clay mineral content is over $10 \%$
, the reservoir is likely to suffer particle migration, hydration swelling and velocity sensitivity, etc. The deficiency of X-ray diffraction analysis is that it can only determine the types and contents of clay minerals, but not the forms of clay minerals and their occurrence features in reservoir pores while the latter ones affect greatly the reservoir sensitivity, even more than the former ones. The forms of clay minerals and their occurrence features can only be obtained with the help of scanning electron microscope or thin section analysis.

It is found through scanning electron microscope and cast thin section analysis in combination with the research into diagenesis and pore evolution of the formations that the sandstone particles in the reservoir are enclosed by cement with no clear dividing lines between particles. The particles contact each other in mosaic manner and the minerals are usually distributed on the surface of the particles in thin layers or packed in the pores between particles in bridging manner. The intergranular pores are not well developed and the pore categories are complicated. Secondary pores take the lead, including intergranular dissolved pores, dissolved pores inside particles, and moldic pores, etc, followed by small amount of residual primary pores. Therefore, the reservoir is prone to the potential damage from water sensitivity, acid sensitivity and velocity sensitivity.

\section{Analysis of sensitivity damage features of the reservoir}

Another important factor that might influence water injection results is the sensitivity of reservoirs, including water sensitivity, velocity sensitivity, salt sensitivity, alkaline sensitivity, acid sensitivity and pressure sensitivity. The paper analyzes the damage degrees of reservoir sensitivities through tests.

Clay minerals reach expansion equilibrium with formation water in the original conditions of the formations and the original conditions will be disturbed when external fluids invade the formations, which might cause the clay to swell quickly, blocking the pores ${ }^{[2]}$. The purpose of water sensitivity tests is to understand the process of clay swelling, dispersing and migrating when incompatible external fluids enter the reservoir and the final degree of reservoir permeability decrease induced. The tests indicated (Table 5) that Well H2-9-5219 suffered water sensitivity damage around the $2816.5 \mathrm{~m}$ interval and the damage degree was moderate to weak. Therefore, clay swelling due to water sensitivity is an important reason for high water injection pressure.

Salt sensitivity tests were conducted in order to further determine the water sensitivity of the reservoir and understand the changing process of permeability when the salinity of formation water was decreasing constantly or salt water with low salinity was used in the field and find out the critical salinity when permeability decreased obviously. The tests indicated (Fig.1) that permeability of the core dropped by over $10 \%$ when salinity of the salt water decreased from $3000 \mathrm{mg} / \mathrm{L}$ to $2000 \mathrm{mg} / \mathrm{L}$, so the critical 
salinity of the core was $3000 \mathrm{mg} / \mathrm{L}$. It is recommended that salinity of injected water should be maintained at over $3000 \mathrm{mg} / \mathrm{L}$ to prevent water sensitivity of the reservoir from taking place.

There are always very fine particles existing in the formations to varying degrees and they are usually not cemented to fixed positions, but exit as unconsolidated particles on the surface of pore walls or inner surface of matrix particles and they can migrate with the fluids in the pores and accumulate at the throats, reducing greatly formation permeability ${ }^{[3]}$. Six velocity sensitivity tests were conducted using the cores form Well H2-9-5219 and the results indicated that (Table 6) velocity sensitivity damage did exist and the degree of damage was moderate to weak or moderate.

Three volume flow rate tests were also conducted (Fig.2) and similar changing patterns were exhibited: the fluid phase permeability showed a stable declining trend as the cumulated injected PV value increased. The injection pressure increased as the cumulative injected PV value increased, but fluctuated during the increasing process. The sensitivity degree to volume flow rate was evaluated by using volume sensitivity index and the damage degree was moderate or moderate to weak. However there was one problem worth mentioning that was the decline trend of permeability of the three cores did not stop, which indicated the internal structures of the cores had not reached a stable state and the damage to permeability would increase if things went on like this for a long time, leading to the increase of water injection pressure in the end.

Forward and counter flow tests were conducted to further prove the existence of particle migration and analyze the reasons for fluid phase permeability decrease (Fig.3). Forward and counter flow tests were conducted with the forward flow of fluid at first, followed by counter flow of the same fluid at the same flowing velocity without interruption of the flow. If there were unconsolidated fine particles in the core, the fine particles would come off and migrate during the forward and counter flow tests, increasing or eliminating bridge plugs, leading to the fluctuation of permeability of the core. Therefore, the tests could be used to observe the stability of the cementation of the core and whether fine particles migrate in the core. The results of the tests indicated that fine particles migrated moderately in the cores. The fluid phase permeability during the first forward flow was greater than that of the second forward flow. The fluid phase permeability during the first forward flow dropped substantially while the fluid phase permeability during the second forward flow stayed fairly stable. The injection pressure during the second forward flow was greater than that of the first forward flow. During the tests, the pressure fluctuated with the increase of cumulated PV value. During water injection, fine particles migrated in the reservoir to varying degrees.

To further find out the source of migrating fine particles, grain size analysis was conducted with laser particle size analyzer on injected water and displaced injected water
(Fig.4). The shading degree of the injected water was zero, indicating no particles observed in the injected water in such inspection conditions. However, particles were found out in the displaced injected water. It could be seen from the grain size analysis tests that the average grain size of the particles in the displaced injected water was $21.133 \mu \mathrm{m}$, bigger than the diameter of the pore throats. Particles with the grain size smaller than or equal to $1 / 3$ of the diameter of pore throats accounted for nearly $24 \%$ of the total fine particles and those between $1 / 3$ of the diameter of the pore throats and $2 / 3$ of the diameter of the pore throats accounted for about $9 \%$. Grain size grades and particle concentration were the major factors affecting particle plugging. When the particle size was close to $1 / 3 \sim 2 / 3$ of the pores, the particles were very likely to cause plugging and the greater the particle concentration, the more likely it would cause plugging. The particles of the two above mentioned grades took up over $30 \%$ of the total fine particles. Therefore particles migrated during water injection and those particles with the grain size smaller than the diameter of the pore throats were displaced out of the cores and those larger particles caused plugging in the cores. This was the cause of permeability decrease during water injection. The following conclusion can be drawn from the grain size analysis: fine particles did migrate in the core of the reservoir during water injection. The migrating fine particles came primarily from the inside of the reservoir. The fine particles in the reservoir were eroded, came off and migrated, plugging the filtration porous channels and causing reservoir damage. Different formation should have different acidizing fluid formula. If the formula is not suitable, the formation conditions will not be improved, and the production will not be improved either. On the contrary, the formation will be damaged. The so called acid sensitivity refers to the phenomenon in which acidizing fluids react with acid sensitive minerals in the formation, generating deposits or releasing fine particles and reducing the permeability of formations. The purpose of acid sensitivity evaluation is to understand whether acidizing fluids will cause formation damage and the damage degree, if any, so as to optimally select the acidizing fluid formula and find out the most effective acidizing method. It can be seen from the acid sensitivity evaluation tests that (Table 7) Well H2-9-5219 suffered acid sensitivity damage around the $2826.3 \mathrm{~m}$ interval of the core. The acid sensitivity damage degree was moderate. The major reason for acid sensitivity damage was that the core had a certain amount of chlorite in the $2826.3 \mathrm{~m}$ interval in the well and chlorite released ferric ions when contacted with hydrochloric acid solution. When the acidizing fluid was consumed and PH value increased, the ferric ions would deposit and cause acid sensitivity damage.

The results of water quality analysis indicated (Table 8 and 9) that both the formation water and the injected water did not have $\mathrm{Sr}^{2+}$ and $\mathrm{Ba}^{2+}$, so it was impossible to generate barium sulfate and strontium sulfate. However it can be seen from the predicted results (Table 10) that the formation 
water and injected water both had the tendency of $\mathrm{CaCO}_{3}$ scaling to a certain degree and the $\mathrm{CaCO}_{3}$ scaling tendency index of the injected water was higher than that of the formation water. When the reservoir has $\mathrm{CaCO}_{3}$ and $\mathrm{CaSO}_{4}$ generated, they will both adhere to the inner surface of the pore throats, reducing the flow radius of the throats and affecting reservoir permeability and causing water injection pressure to increase and formation water injection capacity to decrease.

Generally speaking, the stress sensitivity of low permeability reservoirs is stronger than that of the medium to high permeability reservoirs ${ }^{[4]}$, so it is even more important to evaluate the stress sensitivity of the low permeability reservoir DuJiaTai. Based on the stress sensitivity tests on Well H2-9-5219(Table 11), it can be seen that permeability of the core changed obviously when the annular pressure was increased to $5 \mathrm{MPa}$, which was regarded as the critical stress. Therefore the critical stress value of the core should be 5MPa. In terms of stress damage degree, the reservoir damage degree was weak or moderate to weak.

\section{Research of protective methods from reservoirs damage}

In view of the clay swelling phenomenon in the reservoir, two kinds of anti-swelling agents $\mathrm{A}$ and $\mathrm{B}$ were selected to conduct clay anti-swelling tests. It can be seen (Table 12) that the two agents both had some anti-swellling effects, reducing the clay swelling ratio with the treated waste water from Station X7 from $5.3 \%$ to $1.79 \%$ and $2.31 \%$ respectively. The anti-swelling effects were better when $10 \%$ antiswellling agent A was added. To further study the antiswelling effects of the reservoir clay of the block, test procedure of $\mathrm{KOH}$ solution treatment was designed.

$2 \% \mathrm{KCl}$ solution was used as the pretreatment fluid to replace the bivalence cations in the reservoir. Because the reservoir had bivalence cations, such as $\mathrm{Mg}^{2+}$ and $\mathrm{Ca}^{2+}$, which could form insoluble deposits in contact with $\mathrm{KOH}$ solution, blocking the bottomhole and achieving the undesired treatment results, so $\mathrm{KCl}$ was required before $\mathrm{KOH}$ solution treatment to replace the bivalence cations in the core. Because the impurities in $\mathrm{KCl}$ solution were mostly bivalence cations, which required to be replaced during $\mathrm{KCl}$ pretreatment, so high purity $\mathrm{KCl}$ was required to ensure complete replacement of the bivalence cations and the volume of pretreatment fluid $\mathrm{KCl}$ should be greater than that of $\mathrm{KOH}$ solution. The treatment with $\mathrm{KCl}$ lasted for 24 hours. After treatment, the clay linear swelling ratio of the core was measured to be $1.124 \%$. The concentration of $\mathrm{KOH}$ solution was $15 \%$ and the core was exposed to $\mathrm{KOH}$ solution completely. After treatment for 24 hours, the clay swelling ratio was measured to be $1.168 \%$ and $1.081 \%$ after 48hours. To meet the requirements of water re-injection after $\mathrm{KOH}$ treatment, the treated waste water $(\mathrm{PH}=9)$ from $\mathrm{X} 7$ zhan with antiswelling agent $\mathrm{A}$ or $\mathrm{B}$ added was used during the later treatment stage and again the volume of the post treatment fluid was much greater than that of the $\mathrm{KOH}$ solution. 24 hours later, the swelling ratio of clay was measured to be $1.081 \%$ and 120 hours later, it was measured to be $1.103 \%$, which indicated that clay minerals in the core could stay stable durably after being treated by $\mathrm{KOH}$ solution. The reason behind was that $\mathrm{KOH}$ could change smectite into non-swelling offretite at the temperatures of $20 \sim 85$, therefore reducing the hydration swelling and particle migration of clay minerals. The $\mathrm{KOH}$ solution dynamic simulation tests were conducted by using the method of core flow test. The concentration of $\mathrm{KCl}$ pretreatment agent solution was $2 \%$ to replace the bivalence cations and prevent precipitation from taking place during $\mathrm{KOH}$ solution injection. During the core treatment by $2 \% \mathrm{KCl}$, the permeability of the core did not change much and stayed fairly stable. The concentration of $\mathrm{KOH}$ solution was $15 \%$ to enable the core exposed to the solution completely and reach the purpose of antiswelling. During the soaking of the core in $15 \% \mathrm{KOH}$ solution, the permeability of the core began to decrease two hours later due to alkaline sensitivity damage. After treating by $2 \%$ $\mathrm{KCl}$ and $15 \% \mathrm{KOH}$ solutions, simulation injection was conducted by using the treated waste water from X7zhan. During the injection of the treated waste water from X7zhan, the permeability of the core decreased somewhat due to mainly clay swelling.

During the static simulation tests of $\mathrm{KOH}$ solution treatment, the test results were reflected by the measured swelling ratios. $\mathrm{KOH}$ solution could stabilize the clay so as to reduce hydration swelling and particle migration of clay minerals. In the dynamic simulation tests, the alkaline sensitivity damage induced by the high concentration alkaline solution caused the clay minerals to release fine particles, blocking the pores and throats under the action of injected fluids and reducing permeability. After the injection of the treated waste water from X7zhan, the permeability of the core decreased a little bit due to clay swelling. Therefore, $\mathrm{KOH}$ solution treatment achieved better results in the static test while in the dynamic test, alkaline sensitivity damage might result in reservoir damage, so no $\mathrm{KOH}$ treatment should be conducted to alkaline sensitive formations. Organic anti-swelling agents, such as anti-swelling agent A can be used instead.

Four kinds of acidizing fluid formulas were studied to conduct the corrosion ratio tests on core debris. Simulated formation water was used as the injected fluid to evaluate permeability changes with formula $\mathrm{A}, \mathrm{B}, \mathrm{C}$ and $\mathrm{D}$. The test results indicated (Table 13) that permeability of the core increased notably and injection pressure decreased substantially after acidizing treatment, achieving good results in terms of block removal, pressure reduction and injection improvement.

Water-gas alternating injection is a recovery method in which injection of a water slug/gas slug is followed closely by a gas slug/water $\operatorname{slug}^{[5][6]}$. During the alternating injection, besides water flooding, nitrogen can be used in gas flooding to improve the displacement efficiency. By water-nitrogen alternating injection, scaling and water 
sensitivity damage caused by water injection can be reduced to a certain degree. By using the artificial cores packed by debris from Well H2-9-5219, water-nitrogen alternating injection tests were conducted in different injection ways to analyze the effects of alternating injection on displacement efficiency. The NO. 1 core was tested with water flooding, one cycle, two cycles and three cycles of alternating injection and water flooding. The No.2 core was tested with gas flooding, one cycle, two cycles and three cycles of alternating injection and water flooding. The test results indicated (Table 14 and Fig.5) that water-nitrogen alternating injection could improve effectively the displacement efficiency after both water flooding and gas flooding, but "nitrogen flooding + water-nitrogen alternating injection" was better than "water flooding + water-nitrogen alternating injection".

\section{Conclusions}

The development of Dujiatai reservoir by water injection was not satisfactory due to high injection pressure and poor water injection capacity, which was caused mainly by reservoir damage during water injection. It was found through tests that microscopic pore throat structure was the root cause for reservoir damage and water sensitivity, velocity sensitivity, salt sensitivity, alkaline sensitivity and pressure sensitivity are the potential factors for reservoir damage. Clay swelling and particle migration are the major reservoir damage categories. Antiswelling agents, in depth acidizing and water-gas alternating injection can reduce the reservoir damage degree, but the effects need to be further proved in field tests. Based on the complexity of Dujiatai reservoir, it is recommended to conduct development tests other than water injection to avoid reservoir damage.

\section{Acknowledgements}

The author would like to express his sincere gratitude to the Fracturing \& Acidizing Center of Drilling and Production Technology Research Institute of Liaohe Oilfield Company, PetroChina and the Geology Research Institute of Huanxiling Oilfield, PetroChina for their support and assistance in completing the paper.

\section{References}

[1] Yao Weiying: “Accurate Reservoir Description Research of the Low Permeability Formation in Dujiatai of Northern Huanxiling Oilfield", Special Oil \& Gas Reservoirs, [J], 14(2), 2007;

[2] Zhang Ying, Fu Dekui and Qi Xianyou: "Optimization Research of the Quality of Injected Water in the Low Permeability Reservoir of Dujiatai in Northern Huanxiling Oilfield", Special Oil \& Gas Reservoirs, [J], 10(S1), 2003;

[3] Zhou Zongqiang, Xu Yonggao and Wang Xiaoduo:

"Evaluation of Fine Particle Migration in Sulige Gas Field Reservoir and Analysis of Preventive Measures", Natural Gas Industry, [J]. 25(1): 69

[4] Zhou Boran, Lin Cunzeng and Tian Zhongyan:"Test Study of Petrophysical Property during Water Injection”, proceedings of 1996 International Workshop on Well Logging during Water Flooding Development, Petroleum Industry Press, Sept. 1996, 20-33

[5] Cao Xueliang, Guo Ping, Yang Xuefeng and Li Shilun: "Analysis of the Feasibility of Improving Recovery Factor by Gas Injection in Low Permeability Reservoirs", Natural Gas Industry, [J]. 26(1): 2006

[6] He Qiuxuan and Wang Zhiwei: "Research into Gas Injection Development of Low

Permeability Oilfields", Petroleum Geology and Recovery Efficiency, [J], 9(6), 2002. 
Table 1. Classification of pore structure in DuJiaTai reservoir

\begin{tabular}{|c|c|c|c|c|c|c|c|}
\hline \multirow{2}{*}{$\begin{array}{l}\text { Physical } \\
\text { property }\end{array}$} & \multicolumn{3}{|c|}{ Pore structure category } & \multirow{2}{*}{$\begin{array}{l}\text { Average width of } \\
\text { pore }(\mu \mathrm{m})\end{array}$} & \multirow{2}{*}{$\begin{array}{c}\text { Max. width of } \\
\text { pore }(\mu \mathrm{m})\end{array}$} & \multirow{2}{*}{$\begin{array}{l}\text { Coordinate } \\
\text { number }\end{array}$} & \multirow[b]{2}{*}{ Pore/throat } \\
\hline & pore & throat & uniformity & & & & \\
\hline \multirow{2}{*}{$\begin{array}{c}\text { Medium } \\
\text { permeability }\end{array}$} & \multirow{2}{*}{ big } & small & fair & 107.53 & 555 & 2.75 & 14.41 \\
\hline & & small & not & & & & \\
\hline \multirow{2}{*}{$\begin{array}{c}\text { Low } \\
\text { permeability }\end{array}$} & \multirow{2}{*}{ medium } & small & fair & 67.07 & 465 & 1.77 & 25.16 \\
\hline & & small & not & 89.3 & 215 & 2.80 & 10.29 \\
\hline \multirow{2}{*}{ Extra low } & \multirow{2}{*}{ medium } & tiny & fair & 53.75 & 275 & 1.48 & 330.93 \\
\hline & & tiny & not & 80.06 & 416 & 2.66 & 71.17 \\
\hline
\end{tabular}

Table 2. Statistics of pore structure parameters of DuJiaTai reservoir

\begin{tabular}{|c|c|c|c|c|c|c|c|c|c|}
\hline \multirow{2}{*}{$\begin{array}{c}\text { Sedimentary } \\
\text { facies belt }\end{array}$} & \multirow{2}{*}{$\begin{array}{c}\text { Mean } \\
(\mu \mathrm{m})\end{array}$} & \multirow{2}{*}{$\begin{array}{l}\text { Coefficient of } \\
\text { homogeneity }\end{array}$} & \multicolumn{2}{|c|}{$\mathrm{V}(\%)$} & \multirow{2}{*}{$\begin{array}{c}R_{ \pm} \\
(\mu \mathrm{m})\end{array}$} & \multirow{2}{*}{$\begin{array}{l}V_{\text {主 }} \\
(\%) \\
\end{array}$} & \multirow{2}{*}{$\begin{array}{c}\text { Average width of } \\
\text { pore }(\mu \mathrm{m})\end{array}$} & \multirow{2}{*}{$\begin{array}{c}\text { Coordinate } \\
\text { number }\end{array}$} & \multirow{2}{*}{$\begin{array}{c}\text { Max. width of } \\
\text { pore }(\mu \mathrm{m})\end{array}$} \\
\hline & & & $<0.1 \mu \mathrm{m}$ & $>1 \mu \mathrm{m}$ & & & & & \\
\hline Braided channel & 1.58 & 0.16 & 54.8 & 22.8 & 4.0 & 26.9 & 131.9 & 2.23 & 459.0 \\
\hline Interstream cove & 0.85 & 0.16 & 66.5 & 17.3 & 2.4 & 22.0 & 110.64 & 1.77 & 344.8 \\
\hline Frontal lice & 0.80 & 0.18 & 64.7 & 21.9 & 2.4 & 21.0 & 94.45 & 1.83 & 305.8 \\
\hline $\begin{array}{c}\text { Piedmount } \\
\text { subsea apron }\end{array}$ & 3.29 & 0.19 & 48.4 & 35.5 & 8.4 & 26.4 & 130.22 & 2.24 & 391.0 \\
\hline Number of cores & 231 & 231 & 247 & 210 & 247 & 247 & 65 & 65 & 65 \\
\hline
\end{tabular}

Table 3. X-ray diffraction analysis data of core sample from Well H2-9-5219

\begin{tabular}{c|c|c|c|c|c|c|c|c|c|c}
\hline $\begin{array}{c}\text { Well depth } \\
(\mathrm{m})\end{array}$ & $\begin{array}{c}\text { quartz } \\
(\%)\end{array}$ & $\begin{array}{c}\text { analcite } \\
(\%)\end{array}$ & $\begin{array}{c}\text { dolomite } \\
(\%)\end{array}$ & $\begin{array}{c}\text { Potassic } \\
\text { feldspar(\%) }\end{array}$ & $\begin{array}{c}\text { argillite } \\
(\%)\end{array}$ & $\begin{array}{c}\text { Plagioclase } \\
(\%)\end{array}$ & $\begin{array}{c}\text { calcites } \\
(\%)\end{array}$ & $\begin{array}{c}\text { siderite } \\
(\%)\end{array}$ & $\begin{array}{c}\text { clay } \\
(\%)\end{array}$ & $\begin{array}{c}\text { Not detected } \\
(\%)\end{array}$ \\
\hline 2810.0 & 47 & $/$ & 3 & 11 & $/$ & 27 & 5 & $/$ & 7 & $/$ \\
\hline 2816.5 & 29 & 2 & $/$ & $/$ & 13 & 28 & 6 & $/$ & 20 & 2 \\
\hline 2822.0 & 37 & 2 & $/$ & $/$ & 9 & 28 & 16 & 2 & 4 & 2 \\
\hline 2826.3 & 53 & $/$ & $/$ & 10 & $/$ & 27 & 5 & $/$ & 5 & $/$ \\
\hline 2842.0 & 56 & $/$ & $/$ & 10 & $/$ & 25 & 6 & $/$ & 3 & $/$ \\
\hline 2858.0 & 50 & $/$ & $/$ & 10 & $/$ & 24 & 8 & $/$ & 8 & $/$ \\
\hline 2896.5 & 57 & $/$ & $/$ & 11 & $/$ & 27 & $/$ & $/$ & 5 & $/$ \\
\hline
\end{tabular}

Table 4. Analysis of clay minerals of Well H2-9-5219

\begin{tabular}{c|c|c|c|c|c}
\hline Depth $(\mathrm{m})$ & kaolinite(\%) & chlorite(\%) & illite(\%) & illite/smectite interlayer(\%) & Ratio of interlayer(\%) \\
\hline 2810 & 6 & 24 & 39 & 31 & 15 \\
\hline 2826 & 5 & 24 & 33 & 38 & 20 \\
\hline 2842 & 8 & 34 & 30 & 28 & 20 \\
\hline 2858 & 15 & 25 & 33 & 27 & 20 \\
\hline 2896.5 & 2 & 17 & 38 & 43 & 20 \\
\hline
\end{tabular}

Table 5. Results of water sensitivity tests of Well H2-9-5219

\begin{tabular}{|c|c|c|c|c|c|c|c|}
\hline $\begin{array}{l}\text { Core } \\
\text { No. }\end{array}$ & $\begin{array}{l}\text { depth } \\
(\mathrm{m})\end{array}$ & $\begin{array}{c}K_{\text {absolute }} \\
\left(10^{-3} \mu \mathrm{m}^{2}\right) \\
\end{array}$ & $\begin{array}{l}K_{\text {standard brine }} \\
\left(\times 10^{-3} \mu \mathrm{m}^{2}\right)\end{array}$ & $\begin{array}{c}\mathrm{K}_{\text {sub standard brine }} \\
\left(\times 10^{-3} \mu \mathrm{m}^{2}\right)\end{array}$ & $\begin{array}{l}\mathrm{K}_{\text {deionized water }} \\
\left(\times 10^{-3} \mu \mathrm{m}^{2}\right)\end{array}$ & Water sensitivity index & degree \\
\hline 9 & 2816.5 & 0.3747 & 0.0924 & 0.0844 & 0.0591 & 0.36 & Moderate-weak \\
\hline 13 & 2816.5 & 0.2261 & 0.0357 & 0.0301 & 0.0181 & 0.49 & Moderate-weak \\
\hline 14 & 2816.5 & 0.3233 & 0.0782 & 0.0649 & 0.0511 & 0.35 & Moderate-weak \\
\hline 23 & 2816.5 & 0.1304 & 0.0113 & 0.0097 & 0.0068 & 0.40 & Moderate-weak \\
\hline 24 & 2816.5 & 1.0569 & 0.2284 & 0.1985 & 0.1422 & 0.38 & Moderate-weak \\
\hline
\end{tabular}


Table 6. Results of velocity sensitivity tests of Well H2-9-5219

\begin{tabular}{c|c|c|c|c|c|c|c}
\hline $\begin{array}{c}\text { Core } \\
\text { No. }\end{array}$ & $\begin{array}{c}\text { depth } \\
(\mathrm{m})\end{array}$ & $\begin{array}{c}\mathrm{K}_{\mathrm{G}} \\
\left(10^{-3} \mu \mathrm{m}^{2}\right)\end{array}$ & $\begin{array}{c}\mathrm{Kmax} \\
\left(10^{-3} \mu \mathrm{m}^{2}\right)\end{array}$ & $\begin{array}{c}\text { Kmin } \\
\left(10^{-3} \mu \mathrm{m}^{2}\right)\end{array}$ & $\begin{array}{c}\text { Critical flow velocity } \\
(\mathrm{m} / \mathrm{d})\end{array}$ & $\begin{array}{c}\text { Damage ratio of } \\
\text { permeability }(\%)\end{array}$ & \begin{tabular}{c} 
Damage degree \\
\hline 1
\end{tabular} \\
\hline 2826.3 & 0.2747 & 0.0076 & 0.00528 & 0.210 & 0.30 & Moderate-weak \\
\hline 3 & 2826.3 & 0.2524 & 0.0054 & 0.00351 & 0.166 & 0.35 & Moderate-weak \\
\hline 6 & 2826.3 & 0.1971 & 0.00343 & 0.00216 & 0.084 & 0.37 & Moderate-weak \\
\hline 8 & 2826.3 & 0.1153 & 0.0014 & 0.00078 & 0.024 & 0.44 & Moderate \\
\hline 12 & 2826.3 & 0.1983 & 0.0046 & 0.0023 & 0.351 & 0.50 & Moderate-weak \\
\hline
\end{tabular}

Table 7. Data of acid sensitivity tests of Well H2-9-5219

\begin{tabular}{|c|c|c|c|c|c|c|}
\hline $\begin{array}{l}\text { Core } \\
\text { No. }\end{array}$ & $\begin{array}{l}\text { Well depth } \\
(\mathrm{m})\end{array}$ & Acidizing fluid & $\begin{array}{l}\text { Permeability defore acid } \\
\text { injection }\left(\times 10^{-3} \mu \mathrm{m}^{2}\right)\end{array}$ & $\begin{array}{c}\text { Permeability after acid } \\
\text { injection }\left(\times 10^{-3} \mu^{2}\right)\end{array}$ & Acid sensitivity index & $\begin{array}{c}\text { Degree of acid } \\
\text { sensitivity }\end{array}$ \\
\hline 28 & 2826.3 & $15 \% \mathrm{HCl}$ & 0.00770 & 0.00365 & 0.53 & Moderate \\
\hline 30 & 2826.3 & $15 \% \mathrm{HCl}$ & 0.00520 & 0.00285 & 0.45 & Moderate \\
\hline 31 & 2826.3 & $12 \% \mathrm{HCl}+3 \% \mathrm{HF}$ & 20.00830 & 0.00481 & 0.42 & Moderate \\
\hline 32 & 2826.3 & $12 \% \mathrm{HCl}+3 \% \mathrm{HF}$ & 0.00642 & 0.00405 & 0.37 & Moderate \\
\hline
\end{tabular}

Table 8. Analysis results of formation water quality in DuJiaTai reservoir

\begin{tabular}{|c|c|c|c|c|c|c|c|c|c|}
\hline \multirow{2}{*}{$\begin{array}{l}\text { Well } \\
\text { No. }\end{array}$} & \multicolumn{3}{|c|}{ Cation content $(\mathrm{mg} / \mathrm{l})$} & \multicolumn{4}{|c|}{ Anion content(mg/l) } & \multirow{2}{*}{$\begin{array}{c}\text { Total salinity } \\
(\mathrm{mg} / \mathrm{l})\end{array}$} & \multirow{2}{*}{ Water type } \\
\hline & $\mathrm{Na}^{+}+\mathrm{K}^{+}$ & $\mathrm{Mg}^{+}$ & $\mathrm{Ca}^{+}$ & $\mathrm{Cl}^{-}$ & $\mathrm{SO}_{4}{ }^{2-}$ & $\mathrm{HCO}_{3}^{-}$ & $\mathrm{CO}_{3}{ }^{2-}$ & & \\
\hline $10-5217$ & 1522.6 & 6.1 & 14 & 531.8 & 19.2 & 3051 & 60 & 5204.7 & $\mathrm{NaHCO}_{3}$ \\
\hline $9-5217$ & 1074.1 & 1.2 & 16 & 443.1 & 4.8 & 2074.7 & 30 & 3643.9 & $\mathrm{NaHCO}_{3}$ \\
\hline $9-5217$ & 1131.6 & 3.6 & 8 & 443.1 & 19.2 & 2135.7 & 60 & 3801.2 & $\mathrm{NaHCO}_{3}$ \\
\hline $9-5216$ & 719.9 & 17 & 26.1 & 443.1 & 1 & 1067.9 & 120 & 2394 & $\mathrm{NaHCO}_{3}$ \\
\hline
\end{tabular}

Table 9. Analysis results of injected water quality in DuJiaTai reservoir

\begin{tabular}{|c|c|c|c|c|c|c|c|c|c|c|}
\hline \multirow{2}{*}{ Well No. } & \multicolumn{3}{|c|}{ Cation content (mg/l) } & \multicolumn{4}{|c|}{ Anion content $(\mathrm{mg} / \mathrm{l})$} & \multirow{2}{*}{$\begin{array}{l}\text { Total } \\
\text { iron } \\
\end{array}$} & \multirow{2}{*}{$\begin{array}{c}\text { Total } \\
\text { salinity }(\mathrm{mg} / \mathrm{l})\end{array}$} & \multirow{2}{*}{ Water type } \\
\hline & $\mathrm{Na}^{+}+\mathrm{K}^{+}$ & $\mathrm{Mg}^{+}$ & $\mathrm{Ca}^{+}$ & $\mathrm{Cl}^{-}$ & $\mathrm{SO}_{4}^{2-}$ & $\mathrm{HCO}_{3}^{-}$ & $\mathrm{CO}_{3}{ }^{2-}$ & & & \\
\hline $9-5219$ & 886.5 & 9.053 & 104.4 & 824.21 & 1 & 1420.3 & 95.24 & 1 & 3370.62 & $\mathrm{NaHCO}_{3}$ \\
\hline X7zhan & 921.4 & 10.56 & 102.71 & 806.49 & 1 & 1517.14 & 63.49 & 1 & 3455.3 & $\mathrm{NaHCO}_{3}$ \\
\hline Qingshui & 92.7 & 8.8 & 57.7 & 69.8 & 34.6 & 206.2 & 93.6 & 0.24 & 563.4 & $\mathrm{NaHCO}_{3}$ \\
\hline
\end{tabular}

Table 10. Prediction of scaling tendency of water sample from DuJiaTai reservoir

\begin{tabular}{l|c|c|c|c|c|c}
\hline \multirow{2}{*}{ Water sample source } & \multicolumn{2}{|c|}{ Prediction of $\mathrm{CaCO}_{3}$ scaling tendency } & \multicolumn{3}{|c}{ Prediction of CaSO $\mathrm{S}_{4}$ scaling tendency } \\
\cline { 2 - 7 } & $\mathrm{SI}$ & evaluation & $\mathrm{S}$ & $\mathrm{C}$ & $\mathrm{S}-\mathrm{C}$ & evaluation \\
\hline 10-5217 formation water & 1.48 & yes & 1.67 & 0.4 & no \\
\hline 9-5217 formation water & 1.17 & yes & 28.84 & 0.4 & 28.44 \\
\hline 9-5219 formation water & 2.089 & yes & 0.084 & 0 & 0.084 & no \\
\hline $\begin{array}{l}\text { Injected water after } \\
\text { treatment in X7zhan }\end{array}$ & 2.074 & yes & 0.086 & 0 & 0.086 & no \\
\hline Clear injected water & 1.732 & yes & 0.130 & 0.720 & -0.59 & no \\
\hline
\end{tabular}


Table 11. Evaluation results of stress sensitivity tests on DuJiaTai reservoir

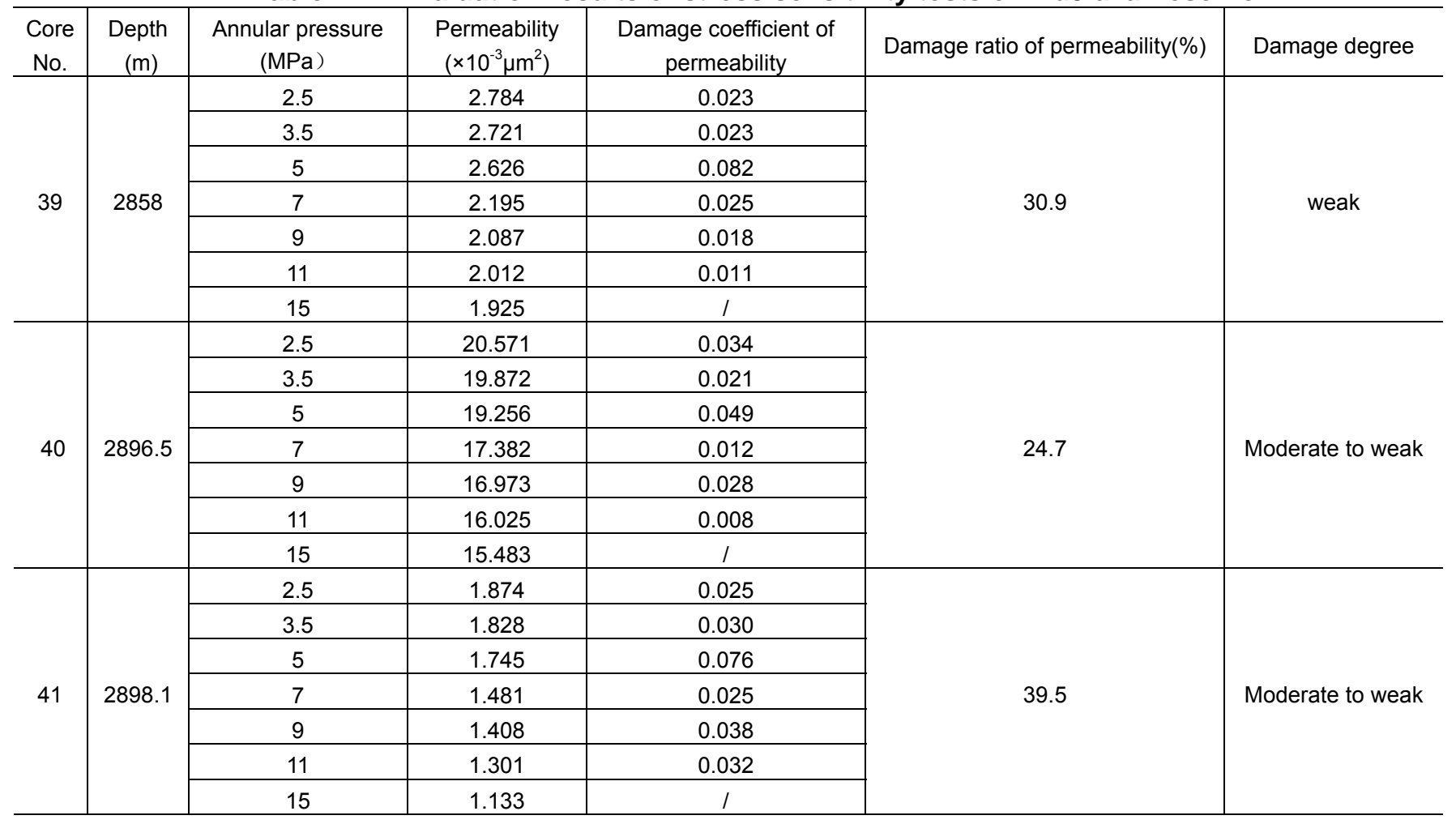

Table 12. Test data of anti-swelling of clay of well H2-9-5219

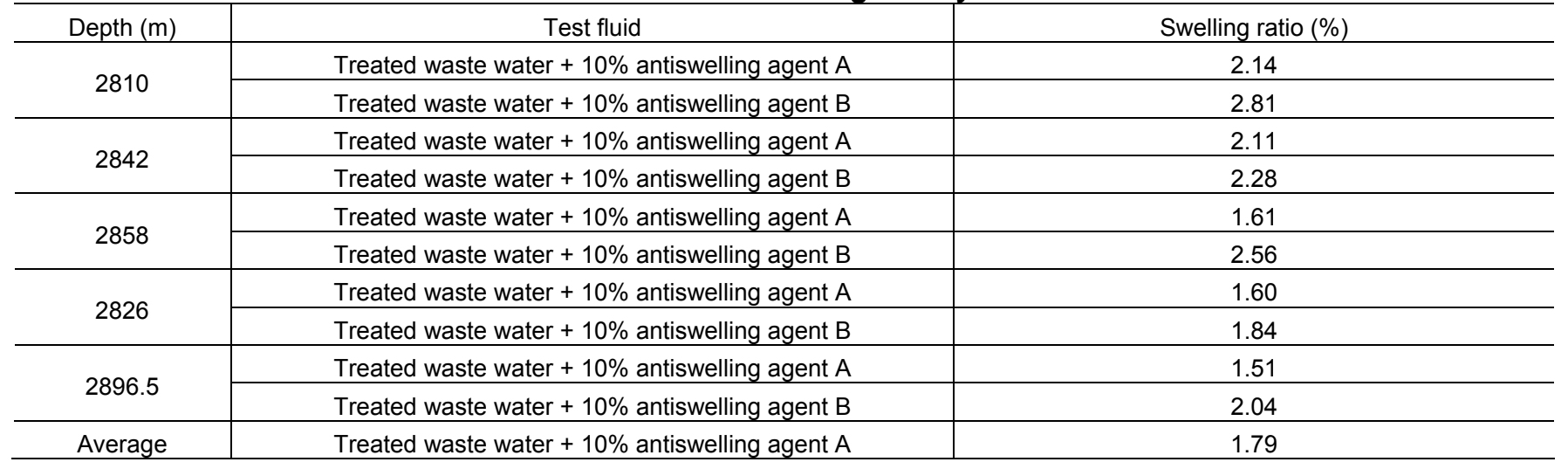

Table 13. Test results of core corrosion ratio by acidizing

\begin{tabular}{c|c|c|c|c|c|c}
\hline $\begin{array}{c}\text { Acidizing fluid } \\
\text { formula }\end{array}$ & $\begin{array}{c}\text { Mass of debris } \\
\text { before acidizing(g) }\end{array}$ & $\begin{array}{c}\text { Mass of debris } \\
\text { after acidizing(g) }\end{array}$ & $\begin{array}{c}\text { Corrosion } \\
\text { ratio(\%) }\end{array}$ & $\begin{array}{c}\mathrm{K}_{\mathrm{Lbefore}} \\
\left(10^{-3} \mu \mathrm{m}^{-2}\right)\end{array}$ & $\begin{array}{c}\mathrm{K}_{\mathrm{Lafter}} \\
\left(10^{-3} \mu \mathrm{m}^{-2}\right)\end{array}$ & $\begin{array}{c}\mathrm{R}_{\mathrm{KL}} \\
(\%)\end{array}$ \\
\hline A & 3 & 2.51 & 16.3 & 0.02259 & 0.52570 & 22.27 \\
\hline B & 3 & 2.58 & 14.0 & 0.02020 & 0.32150 & 14.92 \\
\hline C & 3 & 2.63 & 12.3 & 0.03820 & 0.76610 & 19.05 \\
\hline D & 3 & 2.46 & 18.0 & 0.04920 & 0.30710 & 5.24 \\
\hline
\end{tabular}

Table 14. Comparison of displacement efficiency between different water-gas alternating injections

\begin{tabular}{c|c|c|c|c|c}
\hline \multirow{2}{*}{$\begin{array}{c}\text { No. } 1 \\
\text { core }\end{array}$} & Water flood & 1cycle alternating injection & 2cycles alternating injection & 3cycles alternating injection & Water flood \\
\cline { 2 - 6 } & 60.20 & 60.41 & 60.60 & 63.61 & 63.79 \\
\hline \multirow{2}{*}{$\begin{array}{c}\text { No.2 } \\
\text { core }\end{array}$} & Gas flood & 1cycle alternating injection & 2cycles alternating injection & 3cycles alternating injection & Water flood \\
\cline { 2 - 6 } & 62.44 & 62.44 & 90.89 & 91.67 & 94.44 \\
\hline
\end{tabular}




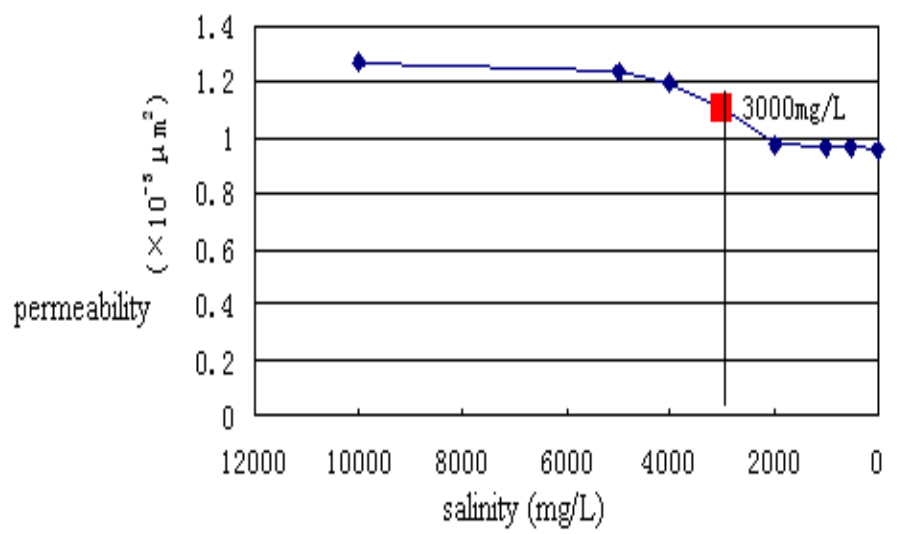

Fig.1 Curve of salt sensitivity test on core at 2898.11m from Well H2-9-5219

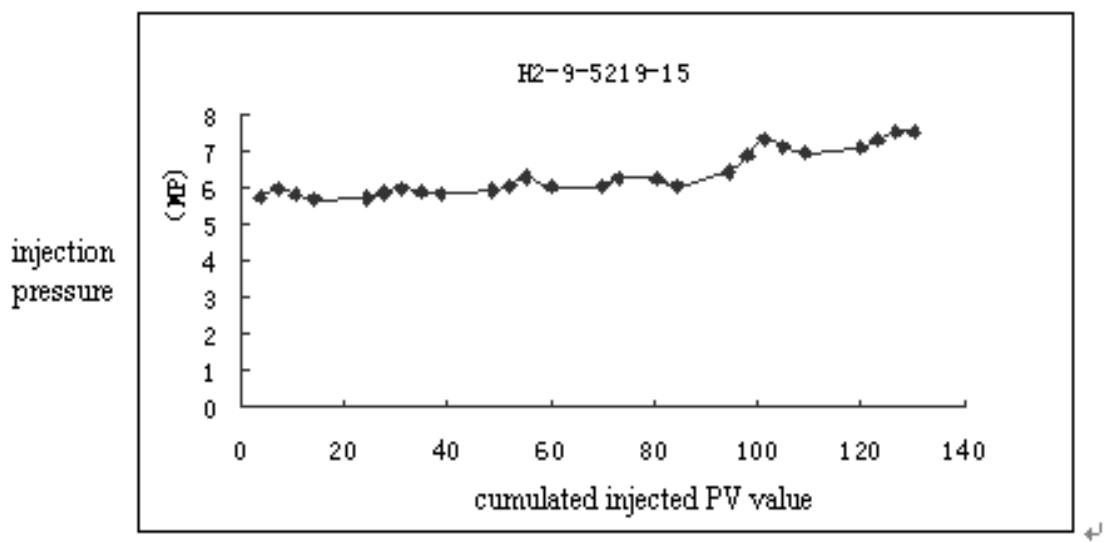

Fig. 2 Relationship between injection pressure and cumulated injected PV value during volume flow rate test

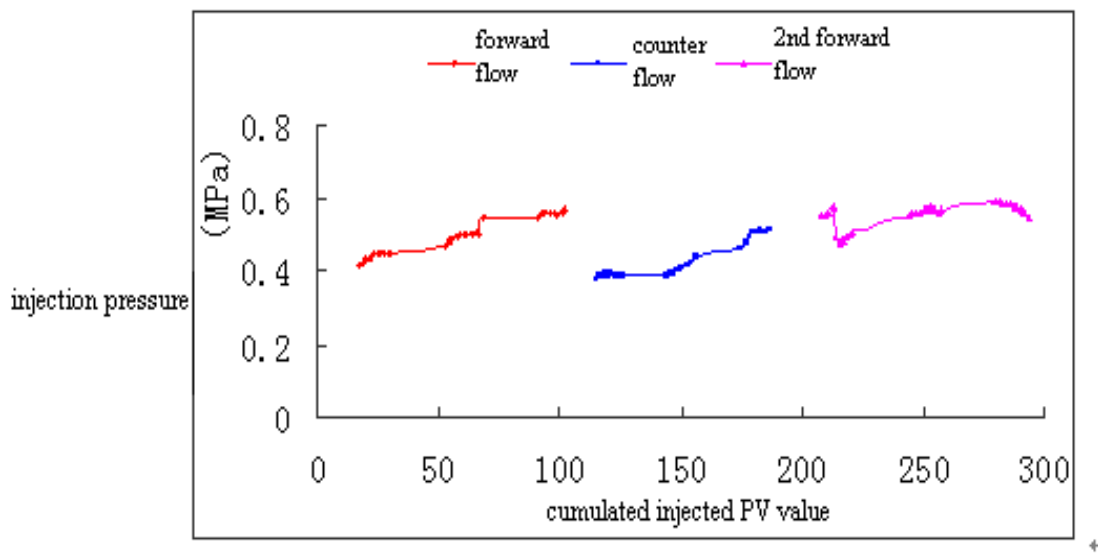

Fig. 3 Relationship between injection pressure and cumulated injected PV value during the forward and counter flow test 


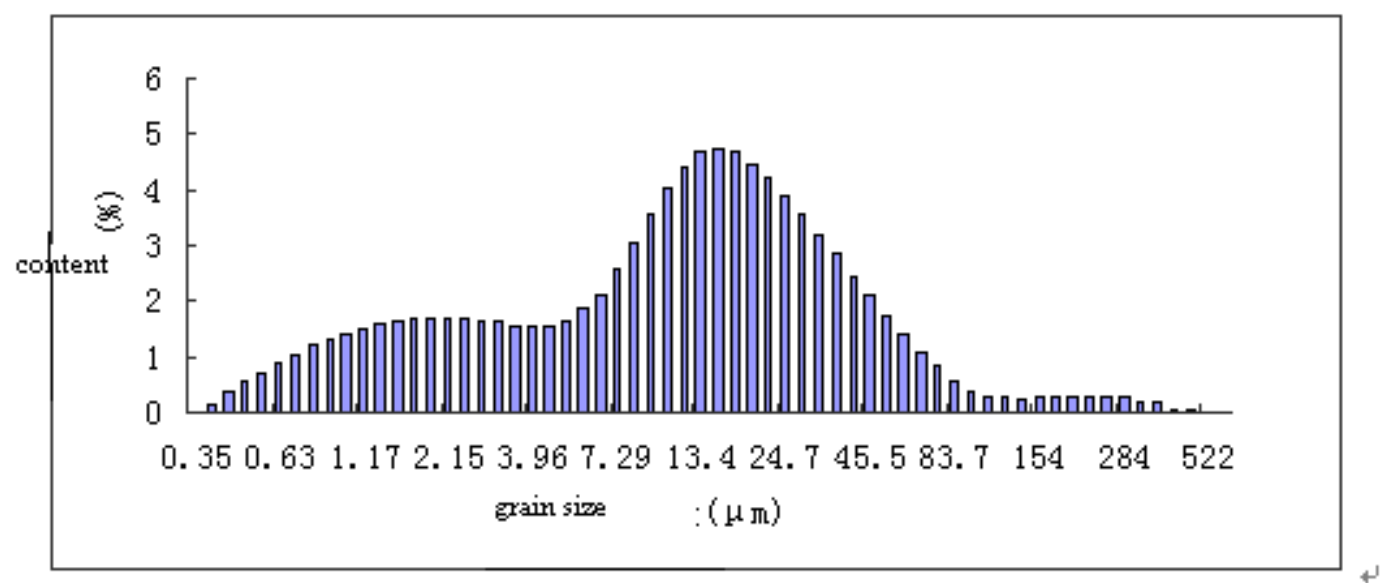

Fig.4 Grain size distribution of particles in displaced injected water

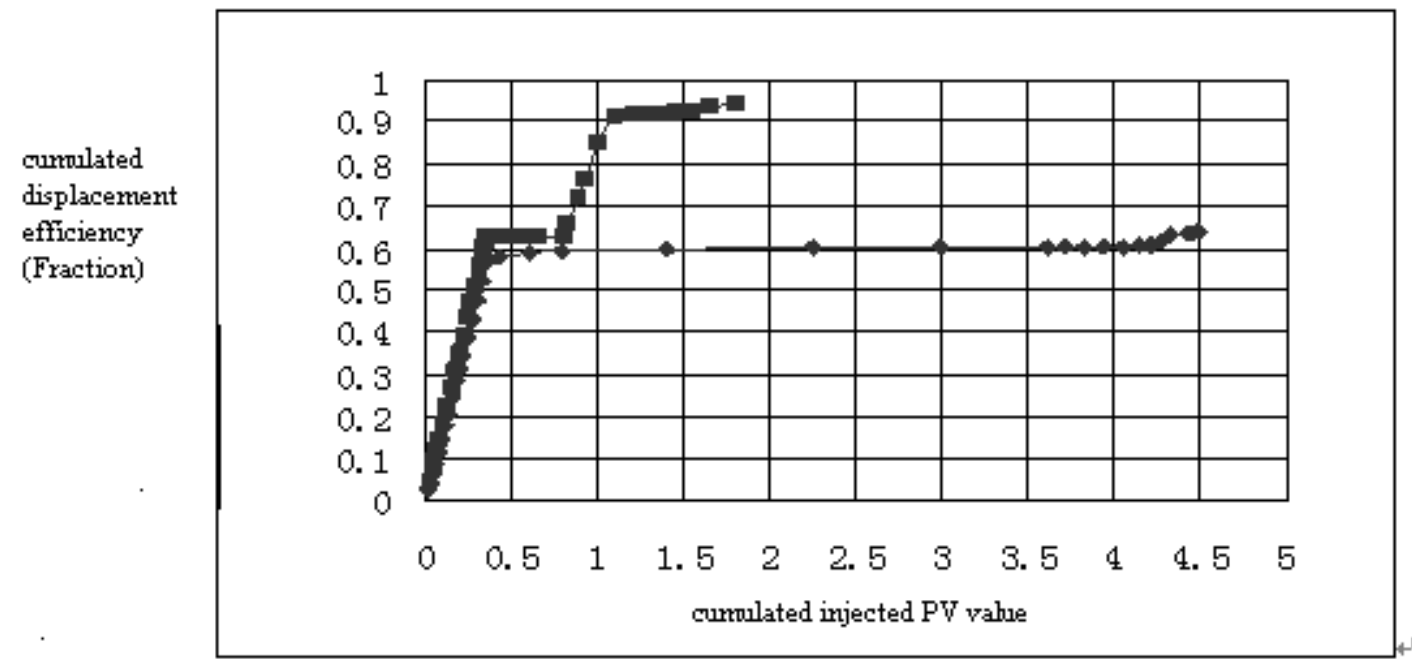

Fig.5 Relationship between displacement efficiency of No.1 and 2 core and cumulated injected PV value 